\title{
Fibromyalgia and rheumatoid arthritis: Personality and psychopathology differences from the Minnesota Multiphasic Personality Inventory-2
}

\author{
Bárbara Gonzalez $^{\mathrm{a}}$, Rosa Novo ${ }^{\mathrm{b}}$, Rodrigo Peres ${ }^{\mathrm{c}, *}$, Telmo Baptista $^{\mathrm{b}}$ \\ ${ }^{\text {a }}$ HEI-Lab: Digital Human-Environment Interactions Lab, Universidade Lusófona de Humanidades e Tecnologias, Avenida do Campo Grande, 376, 1749-024 Lisbon, \\ Portugal \\ ${ }^{\mathrm{b}}$ Faculdade de Psicologia, Universidade de Lisboa, Alameda da Universidade, 1649-013 Lisbon, Portugal \\ ${ }^{\mathrm{c}}$ Instituto de Psicologia, Universidade Federal de Uberlândia, Avenida Pará, 1720, 38400-902 Uberlândia, Brazil
}

A R T I C L E I N F O

\section{Keywords:}

Fibromyalgia

Rheumatoid arthritis

MMPI-2

Personality dimensions

Psychopathology

\begin{abstract}
A B S T R A C T
The fibromyalgia syndrome (FM) is a chronic widespread pain condition whose etiology remains unknown. Within a psychosocial approach to FM, personality may play a role as predisposing and/or maintaining factor. A meta-analytic study has identified a distinct Minnesota Multiphasic Personality Inventory-2 (MMPI-2) clinical profile between FM female patients and healthy controls, but the differences between FM and other chronic pain conditions with clear etiology are not established. This cross-sectional study compares the clinical MMPI-2 profile in FM and rheumatoid arthritis (RA) patients, identifies typical groups of each pathology, and further characterizes these groups in the broad MMPI-2 personality and psychopathology dimensions. The MMPI-2 scales were assessed in a sample of 70 women (FM: $n=38, M_{\text {age }}=46.03, S D_{\text {age }}=8.48$; RA: $n=32$, $M_{\text {age }}=45.31, S D_{\text {age }}=8.68$ ). The FM group had clinically significant elevations on five clinical scales (Hypochondriasis, Depression, Hysteria, Psychasthenia and Schizophrenia), while RA group had none. A K-Means cluster analysis allowed the identification of a typical profile of each pathology, and subsequent MANCOVAs identified important features of FM patients on several MMPI-2 dimensions. We conclude there is specificity in the personality and psychopathology characteristics of FM patients.
\end{abstract}

\section{Introduction}

Fibromyalgia (FM) is a syndrome characterized by chronic widespread pain and tenderness at multiple points, joint stiffness, and related symptoms (e.g., mood disorders, fatigue, cognitive dysfunction, and insomnia) (Mease, 2005), without a well-defined underlying organic disease. The etiology and pathogenesis of FM are still not fully understood, and several aspects seem to be involved, such as dysfunction of the central and autonomic nervous systems, neurotransmitters, hormones, immune system, external stressors, psychiatric aspects, and others (Bellato et al., 2012). The main mechanism involved is central sensitivity, and it is defined by the increased response to stimulation mediated by central nervous system signaling (Yunus, 2008). As the prevalence of FM is considerably higher in women than in men (ratio of 9:1, respectively; Fitzcharles \& Yunus, 2012), most of the studies use female samples, and their findings about psychological features are discussed in terms of female patients only.

The contemporary hypothesis posits that FM emerge in an individual patient when a complex interaction of genetic predisposition, enhanced pain perception, and heightened psychological distress combine with certain environmental factors (Diatchenko, Nackley, Slade, Fillingim, \& Maixner, 2006). Therefore, a biopsychosocial approach is the most appropriate. Van Houdenhove and Egle (2004) proposed a biopsychosocial model of FM, with several etiological factors, as precipitating, predisposing, and perpetuating, suggesting that multiple pathways may lead to the causation and persistence of the syndrome. Specifically, familial-genetic factors, traumatic experiences, lifestyle factors, and previous episodes of depression may increase vulnerability to FM, and various physical, perceptual-cognitive, affective, personality-related, behavioral, and social aspects may perpetuate the illness (Van Houdenhove, Luyten, \& Egle, 2009; Van Houdenhove, Neerinckx, Onghena, Lysens, \& Vertommen, 2001).

Thereby, we are interested in personality as an important aspect in the understanding of FM, both as predisposing and perpetuating, as it is seen as one of a number of modulators or "filters" of psychological responses that might link to the clinical features of FM, in a model of

\footnotetext{
* Corresponding author.

E-mail addresses: barbara.gonzalez@ulusofona.pt (B. Gonzalez), rnovo@psicologia.ulisboa.pt (R. Novo), rodrigosanchesperes@ufu.br (R. Peres), telmob@campus.ul.pt (T. Baptista).
} 
FM linking emotional distress, life events and physical responses (Malin \& Littlejohn, 2012). We also acknowledge that FM patients have higher levels of illness uncertainty than other chronic pain patients with a clearly defined etiology (Reich, Olmsted, \& van Puymbroeck, 2006), the lack of understanding is a common feeling in these women (Juuso, Skär, Olsson, \& Söderberg, 2014) and the invisibility of their pain makes interactions with others more difficult and may bring them further distress (Söderberg, Strand, Haapala, \& Lundman, 2003). Although all these aspects may not be separated in the lives of FM patients, and daily experiences interact with each other and with psychological and physiological features, we consider the structural personality aspects as a basis that can predispose to FM syndrome, within a context of preexisting physiological vulnerability.

The Minnesota Multiphasic Personality Inventory (MMPI) is the most widely used self-report questionnaire for the assessment of personality and psychopathological features in adults, in several contexts (Graham, 2012; Greene, 2000), and it has been extensively used in health and chronic disease contexts (Arbisi \& Butcher, 2004; Ardiç \& Toraman, 2002; Malin \& Littlejohn, 2012), and also with FM patients. It comprises several personality and psychopathology dimensions and enables the control of response attitudes and protocols validity. A recent meta-analysis demonstrated that MMPI has showed to be able to discriminate female patients with FM from healthy volunteers (Novo, Gonzalez, Peres, \& Aguiar, 2017).

Many studies about psychosocial features in FM patients has compared this population with rheumatoid arthritis (RA) patients, because FM and AR are among the most common causes of musculoskeletal pain and disability, and they share a range of associated outcomes, which include not only pain and fatigue but also pervasive difficulties with activities of daily living. Nevertheless, the main difference is that RA has a clear pathophysiology and a range of clinical measures being able to indicate its presence, while FM does not (Walker \& Littlejohn, 2007). In general, studies have identified that FM patients have more depression than AR patients (Hassett, Cone, Patella, \& Sigal, 2000; Wolfe \& Michaud, 2009), worse mental health (Salaffi et al., 2009) and more anxiety and alexithymia, even when the level of depression was controlled (Sayar, Gulec, \& Topbas, 2004).

Pertaining to MMPI results, in cross-sectional studies, FM patients have significantly higher levels than RA patients in Hypochondriasis, Hysteria, and several other clinical scales that refer to greater psychopathology (Psychopathic Deviate, Paranoia, Psychastenia, Schizophrenia, and Hypomania), both in outpatient and in inpatient samples (Ahles, Yunus, Riley, Bradley, \& Masi, 1984; Payne et al., 1982; Wolfe et al., 1984). In a reduced version of MMPI-2 considering only Hypochondriasis, Depression, and Hysteria, Ardiç and Toraman (2002) found significantly higher levels of depression in FM. In a set of statements on the Hypochondriasis, Depression, Hysteria and Schizophrenia scales, FM patients had higher scores on 29 of the 32 statements (Leavitt \& Katz, 1989). In comparison to other chronic pain samples, FM group tends to present significantly higher scores in Hypochondriasis, Depression, Hysteria, Psychasthenia, Schizophrenia and Social Introversion (Trygg, Lundberg, Rosenlund, Timpka, \& Gerdle, 2002), in Hypochondriasis, Depression, Psychasthenia and Schizophrenia (Porter-Moffitt et al., 2006), and in Psychopathic Deviate, Paranoia, Psychasthenia and Schizophrenia (Pérez-Pareja, Sesé, González-Ordi, \& Palmer, 2010).

Pertaining to profile configurations, Keller and Butcher (1991) have found a predominant MMPI clinical profile in the chronic pain patients, mainly characterized by elevations on scales that identify features related to the characteristics identified by Hypochondriasis, Hysteria and Depression scales, which have been named neurotic triad. Comparing FM and RA groups, only $28 \%$ of FM group had the normal profile (i.e., no clinical significant score), while $51-60 \%$ of RA group fitted within this profile (Wolfe et al., 1984), and 31\% of FM group had the psychopathological profile (an elevation of at least four basic clinical scales, comparing with only $6.9 \%$ of RA group, according to Ahles et al., 1984). One study, although cross-sectional, asked FM patients about premorbid aspects, and tried to control for a possible bias of retrospective information. After showing that FM patients showed a significant higher level of action-proneness, when referring to their premorbid style, than the control group, Van Houdenhove et al. (2001) have also showed that these patients significant others, irrespective of their attitude toward the syndrome, have confirmed this information, thereby excluding the hypothesis that these women were idealising their premorbid style. In their biopsychosocial model of fibromyalgia, they speculate that high action-proneness, by promoting an "overactive" lifestyle, may be one of the predisposing factors for the illness, and, simultaneously, contribute to its exacerbation.

Prospective studies in the field of chronic pain are scarse, and even more with FM specifically. However, there are interesting results about the antecedent role of personality in relation to chronic pain onset later in life. A population-based prospective study with 1.658 participants, showed that subjects who were free of chronic widespread pain (a central feature of FM) at baseline had an increased risk of having developed it at follow up, if they displayed features of somatization at baseline, lending powerful support to the hypothesis that chronic widespread pain can be one manifestation of the somatization of distress (McBeth, Macfarlane, Benjamin, \& Silman, 2001). With MMPI/ MMPI-2 specifically, Applegate et al. (2005) identified several clinical scales as predictors of the number of chronic pain conditions 30 years after this personality and psychopathology assessment, in a broad sample of university students. Bigos et al. (1991) identified that Hysteria scale was one of the predictors of a two-fold increase in the probability of developing lower back pain approximately four years later, in sample of 3.020 aircraft employees. Hansen, Biering-Sørensen, and Schroll (1995) following a middle-aged sample over 20 years, found some support for greater incidence of pain in those who had higher scores in the neurotic triad scales before pain onset. However, these results must be considered with care, because of some methodological flaws (Naylor, Boag, \& Gustin, 2017). With other than MMPI dimensions, neuroticism predicted a broad set of physical health problems 25 years later, having a stronger effect in the case of pain conditions (Charles, Gatz, Kato, \& Pedersen, 2008), and also predicted the development of severe neck trouble in a group of workers, migraine among a sample of female health workers, and headache in a broad sample of adolescents (Naylor et al., 2017).

The large majority of studies using MMPI with this population reports only data of clinical scales, and does not explore the scales pertaining to personality psychopathology disorders, content and supplementary scales, which can give a broader and deeper picture of the psychological functioning of FM patients. Thereby, we consider that it would be very useful to explore scales from other MMPI sets of scales, besides the more explored clinical ones, as it has the potential do identify a broad range of personality and psychopathological features that may act as predisposing and perpetuating of the FM syndrome.

This is a cross-sectional study, with two main goals, expressed in two levels of analysis: We want to compare the basic clinical profile of FM and RA patients, in order to identify if there are nuclear clinical features that represent the two different pathologies, and then consider the more representative patients of each pathology as typical groups (TG). We expect a $\mathrm{FM}_{\mathrm{TG}}$ to have more severe psychopathology, beyond the neurotic triad scales. Subsequently, we want to assess the differences between $\mathrm{FM}_{\mathrm{TG}}$ and $\mathrm{RA}_{\mathrm{TG}}$ patients more broadly, in the personality psychopathology, content, and supplementary scales of the MMPI-2. To our knowledge, this is the first study that analyses such a comprehensive set of psychological and psychopathological features, whether in FM patients only or in comparison with RA sample.

\section{Material and methods}

\subsection{Participants}

The participants were 70 women between 30 and 60 years old, 
Table 1

Demographical and clinical characteristics of fibromyalgia (FM) and rheumatoid arthritis (RA) groups.

\begin{tabular}{|c|c|c|c|c|c|c|}
\hline & \multicolumn{2}{|l|}{ FM } & \multicolumn{2}{|l|}{ RA } & \multirow[t]{2}{*}{$F$} & \multirow[t]{2}{*}{$p$} \\
\hline & $M$ & $S D$ & $M$ & $S D$ & & \\
\hline Age & 46.03 & 8.48 & 45.31 & 8.68 & 0.143 & .707 \\
\hline Diagnostic duration & 4.92 & 2.53 & 8.91 & 7.40 & 7.29 & .009 \\
\hline Symptom duration & 12.51 & 8.67 & 11.14 & 8.72 & 0.433 & .513 \\
\hline Pain intensity & 6.29 & 1.56 & 3.91 & 2.02 & 30.47 & .000 \\
\hline
\end{tabular}

\begin{tabular}{|c|c|c|c|c|c|c|c|c|}
\hline & \multicolumn{3}{|l|}{ FM } & \multicolumn{3}{|l|}{ RA } & \multirow[t]{2}{*}{$U$} & \multirow[t]{2}{*}{$p$} \\
\hline & $M d n$ & Min & $\operatorname{Max}$ & $M d n$ & Min & $\operatorname{Max}$ & & \\
\hline \multirow{3}{*}{$\begin{array}{l}\text { Time between symptoms and } \\
\text { diagnosis }\end{array}$} & 4 & 0.50 & 29 & 1 & 0 & 19 & 270.50 & .000 \\
\hline & \multicolumn{2}{|l|}{ FM } & & \multicolumn{2}{|l|}{ RA } & & \multirow[t]{2}{*}{$\chi^{2}$} & \multirow[t]{2}{*}{$p$} \\
\hline & $n$ & $\%$ & & $n$ & $\%$ & & & \\
\hline Civil state & & & & & & & 2.28 & .560 \\
\hline Single & 4 & 11 & & 6 & 19 & & & \\
\hline Married/cohabiting & 27 & 71 & & 20 & 63 & & & \\
\hline Divorced/separated & 7 & 18 & & 5 & 16 & & & \\
\hline Widow & 0 & 0 & & 1 & 3 & & & \\
\hline Academic grade & & & & & & & 9.78 & .125 \\
\hline 1st cycle & 1 & 3 & & 2 & 6 & & & \\
\hline 2nd cycle & 4 & 11 & & 0 & 0 & & & \\
\hline 3rd cycle & 4 & 11 & & 4 & 11 & & & \\
\hline Secondary & 10 & 26 & & 8 & 25 & & & \\
\hline University graduation & 15 & 40 & & 17 & 53 & & & \\
\hline Master & 4 & 11 & & 1 & 3 & & & \\
\hline Professional situation & & & & & & & 4.00 & .279 \\
\hline Working & 26 & 68 & & 27 & 84 & & & \\
\hline Unemployed & 3 & 8 & & 3 & 9 & & & \\
\hline Housewife & 4 & 11 & & 1 & 3 & & & \\
\hline Retired & 5 & 13 & & 1 & 3 & & & \\
\hline
\end{tabular}

Note. FM $(n=38)$; RA $(n=32)$; Min $=$ minimum value for the scale; Max $=$ maximum value for the scale.

divided in two groups: FM group $(n=38)$ and RA group $(n=32)$. The two groups were part of a previously studied wider sample (Gonzalez, 2013) and we now selected less participants of each group in order to obtain a more homogeneous age range. The inclusion criteria for FM and AR patients were: Being $>18$ years old, having a pure FM or RA diagnosis (not having another rheumatic disease or painful condition), having the diagnosis for at least six months and having no psychiatric diagnosis, psychotropic medication and psychological counselling. Finally, the levels of response consistency to the MMPI-2 (obtained through the VRIN and TRIN validity scales) had to be within the normal range, and all the participants had it. The characterization features are presented in Table 1, and besides the sociodemographic variables, the reported pain intensity in the last week is also presented. As the time between the onset of the symptoms and the diagnosis has no normal distribution, we present median and maximum and minimum values, and nonparametric Mann-Whitney test was used to test the differences between the two patients' groups in this variable. We used the ChiSquare test with Monte Carlo simulation for the civil state, academic grade and professional situation, as these variables had some cells with expected count $<5$. The two groups have significant differences in the diagnosis duration in years, time between the onset of the symptoms and diagnosis, and reported pain intensity, being that the AR group had higher diagnosis duration and the FM group had higher time between the onset of the symptoms and diagnosis, and higher reported mean pain.

\subsection{Instruments}

We used the MMPI-2 (Butcher, Dahlstrom, Graham, Tellegen, \& Kaemmer, 1989), in a Portuguese version (Silva, Novo, Prazeres, \& Pires, 2006) to assess clinical and personality psychopathology. It is a self-administered inventory with 567 items, in response format of "True" or "False" categories. The MMPI-2 was designed for evaluating adults who are 18 years of age and older and provide several sets of scales: validity, clinical, content, personality psychopathology, and supplementary. The results obtained in each scale are converted into normalized T-scores, which allows a graphically interpretable profile. In general terms, $\mathrm{T}$-scores higher than 65 are significant and suggestive of possible problems or difficulties. In clinical scales, internal consistency coefficients range between 0.34 and 0.87 , most of them in 0.80 and test-retest coefficients range between 0.54 and 0.93 , most of them in 0.70 . To measure the reported pain intensity, we used the Verbal Numerical Rating Scale, with 11 points, asking the patients to rate the pain they felt in the last seven days, between 0 ("no pain") and 10 ("the worst pain possible"). This scale has a generalized clinical use due to simple administration that favors compliance (Hartrick, Kovan, \& Shapiro, 2003).

\subsection{Procedure}

The FM patients were recruited through the National Association Against Fibromyalgia and Chronic Fatigue Syndrome (MYOS), contacted by telephone and asked about the inclusion criteria and availability to participate in the study. The ones that fulfilled the requirements came to an assessment session in MYOS. The RA patients were recruited through the National Association of Rheumatoid Arthritis Patients (ANDAR), and we followed the same procedure. The patients that fulfilled the requirements came to an assessment session in ANDAR. For both groups, an informed consent was obtained and the privacy was observed in accordance with the principles of the Declaration of Helsinki. The protocol was administered individually, in the form of interview and filled by the main researcher, as according to Edwards, Holmes, and Carvajal (1998), there were no significant differences between self-administration and interview format. We used this format because of the length and great difficulty of self-administration, caused by the attention/concentration and motor functions deficits that characterize both FM and RA. The average duration of the interviews was approximately $90 \mathrm{~min}$.

\subsection{Data analysis}

Data were analyzed using Statistical Package for Social Sciences (v.24 SPSS Inc. Chicago, IL). We divided our analysis into two main steps. In the first step, we used one-way analysis of variance (ANOVA) to test the differences between the FM and RA groups in characterization variables (age, diagnosis duration, symptom duration, reported mean pain intensity and difference between symptom duration and diagnosis duration); we decided to label this last variable "Pain without diagnosis" (PWD), as it represents time in which the symptoms (e.g., pain) were present, but diagnosis had not yet been achieved. Therefore, we consider it could be related to the invisibility and subsequent stigma that has been associated with FM syndrome, as stated in the Introduction. As this variable is strongly non-normal and does not satisfy the conditions for parametric statistic, we made a rank order transformation and used it in the subsequent analysis, as $\mathrm{PWD}_{\text {Ro. }}$ We used correlational coefficients to analyze the potential association among variables in which there were significant differences between the two groups (diagnosis duration, reported mean pain intensity and $\mathrm{PWD}_{\mathrm{Ro}}$ ) and the validity and eight clinical MMPI-2 scales. We excluded Masculinity/Femininity and Social Introversion scales, which are not considered true clinical scales, according to Graham (2012). We used Pearson coefficient for pain intensity, and Spearman coefficient for 
diagnosis duration and $\mathrm{PWD}_{\mathrm{Ro}}$. As reported mean pain intensity and $\mathrm{PWD}_{\mathrm{Ro}}$ had significant correlations with the dependent variables, we used multivariate analysis of covariance (MANCOVA) to test the differences between the FM and RA groups across MMPI-2 validity and clinical scales, controlling for those two variables. We conducted TwoStep cluster analysis and Hierarchical cluster analysis to explore the number of clusters that would spontaneously emerge from the whole sample, based on eight MMPI-2 clinical scales scores. As a two clusters solution was found, we conducted K-means non-hierarchical cluster analysis with the whole sample, in order to identify the distinctive clinical features organizing the two clusters and how the FM and RA patients would be organized within each cluster.

In the second step, in order to explore the differences between the two clusters, we firstly used correlation coefficients to analyze the relation between reported mean pain intensity, diagnosis duration and $\mathrm{PWD}_{\mathrm{Ro}}$ (the three variables in which there were differences between the two clusters) and most of the MMPI-2 clinical, personality psychopathology, supplementary, and content scales, in order to assess when to control for these variables. Thereby, we used MANCOVA with both reported pain and $\mathrm{PWD}_{\mathrm{Ro}}$ as covariates, to test the differences between the two identified clusters across MMPI- 2 clinical and content scales, and we used MANCOVA with $\mathrm{PWD}_{\mathrm{Ro}}$ only as covariate, to test the differences between the two clusters in the personality psychopathology and supplementary scales, as pain showed no significant correlations with these scales.

\section{Results}

\subsection{First step of the analysis}

In this step of analysis, we wanted to compare the clinical basic profile of FM and RA patients, in order to identify if there are nuclear clinical features that represent the two different pathologies. In the set of validity scales, the MANCOVA with the reported pain intensity as covariate showed no significant differences between the FM and RA groups in the composite of eight validity scales (Wilk's $\Lambda=0.911 ; F$ $(8,60)=0.74 ; p=.658)$. Pertaining to the correlations between the $\mathrm{PWD}_{\mathrm{Ro}}$ and the clinical scales, the FM group had only one significant correlation, a positive relation with Hypochondriasis $(r=0.37$, $p<.05)$. In the composite of eight basic clinical scales, the MANCOVA showed significant differences between the two groups (Wilk's $\Lambda=0.759 ; F(8,59)=2.34 ; p=.030 ; \eta^{2}$ par $\left.=0.241\right)$, with the covariate reported pain also being significant (Wilk's $\Lambda=0.746 ; F$ $(8,59)=2.51 ; p=.020 ; \eta^{2}$ par $\left.=0.254\right)$ and the covariate $\mathrm{PWD}_{\mathrm{Ro}}$ not being significant (Wilk's $\Lambda=0.935 ; F(9,59)=0.51 ; p=.844$ ). As presented in Table 2, the FM group had significantly higher scores in six of the eight clinical scales (Hypochondriasis, Depression, Hysteria,

Table 2

Mean T-scores, Standard Deviations and ANCOVAs of MMPI-2 eight clinical scales for fibromyalgia (FM) and rheumatoid arthritis (RA) groups.

\begin{tabular}{|c|c|c|c|c|c|c|c|}
\hline & \multicolumn{2}{|l|}{ FM } & \multicolumn{2}{|l|}{ RA } & \multirow[t]{2}{*}{$F$} & \multirow[t]{2}{*}{$\eta^{2}$} & \multirow[t]{2}{*}{$p$} \\
\hline & $M$ & $S D$ & $M$ & $S D$ & & & \\
\hline Hs & 80.00 & 9.29 & 59.38 & 13.71 & 14.58 & 0.181 & .000 \\
\hline $\mathrm{D}$ & 76.11 & 11.61 & 62.19 & 13.25 & 4.57 & 0.065 & .036 \\
\hline Hy & 76.50 & 11.99 & 56.84 & 13.47 & 10.96 & 0.142 & .002 \\
\hline $\mathrm{Pd}$ & 59.32 & 11.49 & 52.78 & 11.02 & 2.23 & 0.033 & .140 \\
\hline $\mathrm{Pa}$ & 59.34 & 12.40 & 47.63 & 13.27 & 5.98 & 0.083 & .017 \\
\hline $\mathrm{Pt}$ & 64.58 & 11.30 & 51.28 & 10.83 & 5.78 & 0.080 & .019 \\
\hline $\mathrm{Sc}$ & 68.79 & 12.14 & 54.69 & 11.33 & 6.07 & 0.084 & .016 \\
\hline Ma & 57.13 & 8.63 & 53.94 & 11.12 & 0.582 & 0.009 & .448 \\
\hline
\end{tabular}

Note. FM $(n=38) ;$ RA $(n=32) ; \quad$ Hs = Hypochondriasis; $\mathrm{D}=$ Depression; Hy $=$ Hysteria $;$ Pd = Psychopathic Deviate $; \mathrm{Pa}=$ Paranoia $; \mathrm{Pt}=$ Psychasthenia $;$ Sc = Schizophrenia;

$\mathrm{Ma}=$ Hypomania.
Paranoia, Psychasthenia and Schizophrenia), and these were all clinically significant scores, except for Paranoia.

We then wanted to identify the nuclear clinical features that clearly represent the two different pathologies, to identify the more representative patients of each pathology as typical groups and pursue further analysis. In the K-means two-cluster solution, based on the scores on the eight clinical MMPI-2 scales of the whole sample, convergence was achieved due to none or small change in cluster centers after two iterations. The distance between final cluster centers was 52.463. The larger cluster $(n=41)$ was characterized by clinically significant elevations in five clinical scales: Hypochondriasis, Depression, Hysteria, Psychasthenia and Schizophrenia. The other cluster $(n=29)$ had significantly lower center means in seven of the eight clinical scales, and had no clinically significant elevations (T-scores $\geq 65$ ).

The first cluster identified $33 \mathrm{FM}$ patients and eight AR patients, and the second cluster identified five FM patients and 24 AR patients. Based on this distribution, as the first cluster was composed mainly by FM patients ( $87 \%$ of the whole FM sample) and the second cluster was composed mainly by RA patients ( $75 \%$ of the whole RA sample), we considered each of these clusters could be addressed as representative of each pathology most typical profile. We then decided to exclude the other pathology patients of each cluster (five FM patients and eight RA patients), in order to pursue further analysis based on the core clinical MMPI-2 features. Therefore, the FM type cluster $(n=33)$ was labelled FM typical group $\left(\mathrm{FM}_{\mathrm{TG}}\right)$, and the RA type cluster $(n=24)$ was labelled RA typical group $\left(\mathrm{RA}_{\mathrm{TG}}\right)$. We state this classification of typical groups has an exploratory value, in order to enable a further comprehension of the characteristic features of these two types of patients.

The $\mathrm{FM}_{\mathrm{TG}}$ identified 33 participants $\left(M_{\mathrm{age}}=45.70, S D_{\mathrm{age}}=8.90\right)$, with diagnosis duration in years $(M=5.06, S D=2.46)$, symptom duration in years $(M=12.92, S D=9.00)$, PWD in years $(M d n=4$, Minimum $=0.50$, Maximum $=29$ ), and reported mean pain intensity $(M=6.42, \quad S D=1.48)$. The $\mathrm{RA}_{\mathrm{TG}}$ identified 24 participants $\left(M_{\text {age }}=45.54, S D_{\text {age }}=9.41\right)$, with diagnosis duration in years $(M=8.00, S D=7.22)$, symptom duration in years $(M=10.00$, $S D=8.44), \quad$ PWD in years $\quad(M d n=1, \quad$ Minimum $=0$, Maximum $=10.50)$, and reported mean pain intensity $(M=3.50$, $S D=2.04)$. The groups have significant differences in the diagnosis duration, $\mathrm{PWD}$ and reported mean pain intensity, being that the $\mathrm{FM}_{\mathrm{TG}}$ has higher PWD $(U=170.5 ; p=.000)$ and higher pain intensity $(F$ $(1,55)=39.35 ; p=.000)$, while the $\mathrm{RA}_{\mathrm{TG}}$ has higher diagnosis duration $(F(1,55)=4.74 ; p=.034)$.

Pertaining to the significant correlations between $\mathrm{PWD}_{\mathrm{Ro}}$ and MMPI-2 variables, in the FM group there were only four: a positive relation with Hypochondriasis clinical scale $(r=0.39, p<.05)$, and with Repression supplementary scale $(r=0.36, p<.05)$, and a negative correlation with Disconstraint personality psychopathology scale $(r=-0.50, p<.01)$, and with Ego Strength supplementary scale $(r=-0.48, p<.01)$.

The MANCOVA with the $\mathrm{PWD}_{\mathrm{Ro}}$ and the reported pain intensity as covariates confirmed significant differences between the two groups in the composite of clinical scales (Wilk's $\Lambda=0.416 ; F(8,46)=8.06$; $p=.000 ; \eta^{2}$ par $\left.=0.584\right)$, and neither the $\operatorname{PWD}_{\text {Ro }}($ Wilk's $\Lambda=0.929 ; F$ $(8,46)=0.44 ; p=.889$ ), nor the reported pain (Wilk's $\Lambda=0.758 ; F$ $(8,46)=1.83 ; p=.095)$, were significant. We may see in Table 3 that the $\mathrm{FM}_{\mathrm{TG}}$ had significantly higher scores in seven of the eight clinical scales, all except for Hypomania.

\subsection{Second step of the analysis}

We then wanted to assess the differences between the two characteristic patients' groups, in the personality psychopathology, supplementary and content scales. The MANCOVA with the $\mathrm{PWD}_{\mathrm{Ro}}$ as covariate showed significant differences between the two groups in the composite of personality psychopathology scales (Wilk's $\Lambda=0.789 ; F$ $(5,50)=2.68 ; p=.032 ; \eta^{2}$ par $\left.=0.211\right)$, and the $\mathrm{PWD}_{\mathrm{Ro}}$ was not 
Table 3

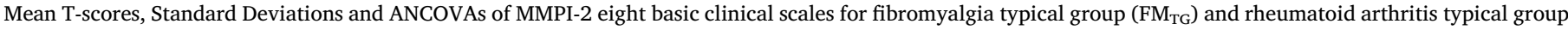
$\left(\mathrm{RA}_{\mathrm{TG}}\right)$.

\begin{tabular}{|c|c|c|c|c|c|c|c|c|c|c|c|}
\hline & \multicolumn{2}{|l|}{$\mathrm{FM}_{\mathrm{TG}}$} & \multicolumn{2}{|l|}{$\mathrm{RA}_{\mathrm{TG}}$} & \multirow[t]{2}{*}{$F$} & \multirow[t]{2}{*}{$\eta^{2}$} & \multirow[t]{2}{*}{$P$} & \multicolumn{2}{|c|}{$\mathrm{FM}_{\mathrm{TG}}(\%)$} & \multicolumn{2}{|c|}{$\mathrm{RA}_{\mathrm{TG}}(\%)$} \\
\hline & $M$ & $S D$ & $M$ & $S D$ & & & & $T \geq 65$ & $T \leq 40$ & $T \geq 65$ & $T \leq 40$ \\
\hline Hs & 81.91 & 8.32 & 55.50 & 12.80 & 24.54 & 0.316 & .000 & 100 & 0 & 21 & 13 \\
\hline D & 78.45 & 10.08 & 57.29 & 8.90 & 26.16 & 0.330 & .000 & 91 & 0 & 29 & 4 \\
\hline Hy & 78.82 & 10.33 & 51.96 & 10.63 & 28.27 & 0.348 & .000 & 91 & 0 & 17 & 13 \\
\hline $\mathrm{Pd}$ & 60.42 & 11.71 & 48.92 & 8.56 & 10.55 & 0.166 & .002 & 30 & 0 & 4 & 17 \\
\hline $\mathrm{Pa}$ & 61.27 & 12.04 & 42.50 & 8.28 & 28.47 & 0.349 & .000 & 36 & 3 & 0 & 42 \\
\hline $\mathrm{Pt}$ & 67.27 & 9.04 & 47.21 & 8.71 & 23.51 & 0.307 & .000 & 58 & 0 & 0 & 33 \\
\hline $\mathrm{Sc}$ & 70.88 & 10.26 & 49.63 & 6.74 & 33.96 & 0.391 & .000 & 73 & 0 & 0 & 8 \\
\hline $\mathrm{Ma}$ & 56.85 & 8.51 & 51.79 & 10.66 & 1.36 & 0.025 & .248 & 21 & 0 & 13 & 8 \\
\hline
\end{tabular}

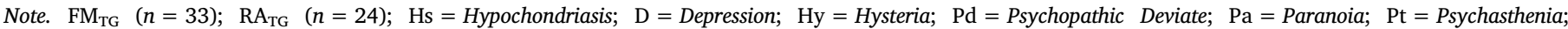
Sc $=$ Schizophrenia; $\mathrm{Ma}=$ Hypomania.

Table 4

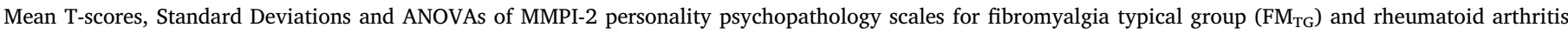
typical group $\left(\mathrm{RA}_{\mathrm{TG}}\right)$.

\begin{tabular}{|c|c|c|c|c|c|c|c|c|c|c|c|}
\hline & \multicolumn{2}{|l|}{$\mathrm{FM}_{\mathrm{TG}}$} & \multicolumn{2}{|l|}{$\mathrm{RA}_{\mathrm{TG}}$} & \multirow[t]{2}{*}{$F$} & \multirow[t]{2}{*}{$\eta^{2}$} & \multirow[t]{2}{*}{$p$} & \multicolumn{2}{|c|}{$\mathrm{FM}_{\mathrm{TG}}(\%)$} & \multicolumn{2}{|c|}{$\mathrm{RA}_{\mathrm{TG}}(\%)$} \\
\hline & $M$ & $S D$ & $M$ & $S D$ & & & & $T \geq 65$ & $T \leq 40$ & $T \geq 65$ & $T \leq 40$ \\
\hline AGGR & 52.18 & 8.90 & 56.58 & 7.99 & 3.42 & 0.060 & .070 & 15 & 0 & 25 & 0 \\
\hline PSYC & 58.21 & 9.15 & 54.58 & 9.39 & 1.59 & 0.029 & .213 & 21 & 0 & 17 & 4 \\
\hline DISC & 46.00 & 6.82 & 46.79 & 7.62 & 0.21 & 0.004 & .650 & 0 & 21 & 0 & 21 \\
\hline NEGE & 59.94 & 11.05 & 52.21 & 9.51 & 7.33 & 0.120 & .009 & 45 & 0 & 17 & 4 \\
\hline INTR & 56.09 & 9.55 & 50.33 & 9.97 & 2.95 & 0.052 & .091 & 21 & 3 & 8 & 17 \\
\hline
\end{tabular}

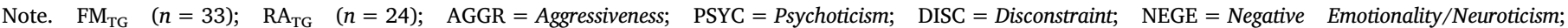
INTR = Introversion/Low Positive Emotionality.

significant (Wilk's $\Lambda=0.924 ; F(5,50)=0.82 ; p=.543$ ). As presented in Table 4, the $\mathrm{FM}_{\mathrm{TG}}$ had significantly higher levels in Negative Emotionality/Neuroticism scale. None of the scales had clinically significant elevations (T-scores $\geq 65$ or $\leq 40$ ) (Graham, 2012).

The MANCOVA showed significant differences between the two groups in the composite of supplementary scales (Wilk's $\Lambda=0.332 ; F$ $(9,46)=10.27 ; p=.000 ; \eta^{2}$ par $\left.=0.668\right)$, and the covariate $\mathrm{PWD}_{\mathrm{Ro}}$ was not significant (Wilk's $\Lambda=0.854, F(9,46)=0.87 ; p=.555$ ). As presented in Table 5, the $\mathrm{FM}_{\mathrm{TG}}$ had significantly higher levels in Anxiety, College Maladjustment, Post-Traumatic Stress Disorder, Marital Distress and Over-Controlled Hostility scales. In contrast, the $\mathrm{FM}_{\mathrm{TG}}$ had significantly lower levels in Ego Strength and Gender Role-Masculine scales. Clinically significant elevations were present in College Maladjustment, Post-Traumatic Stress Disorder (T-scores $\geq 65$ ), and Ego Strength (T-scores $\leq 40$ ) scales.

Finally, the MANCOVA showed significant differences between the two groups in the composite of content scales (Wilk's $\Lambda=0.378 ; F$
$(11,43)=6.44 ; p=.000 ; \eta^{2}$ par $\left.=0.622\right)$. The covariate $\mathrm{PWD}_{\mathrm{Ro}}$ was also significant (Wilk's $\Lambda=0.639 ; \quad F(11,43)=2.21 ; \quad p=.032$; $\eta^{2}$ par $=0.361$ ), and the reported pain was not significant. (Wilk's $\Lambda=0.690 ; F(11,43)=1.76 ; p=.092)$. As presented in Table 6 , the $\mathrm{FM}_{\mathrm{TG}}$ had significantly higher levels in Anxiety, Depression, Health Concerns, Bizarre Mentation, Low Self-Esteem, Family Problems and Work Interference scales. Clinically significant elevations were present in Anxiety and Health Concerns scales only (T-scores $\geq 65$ ). It is relevant that $48 \%$ of the $\mathrm{FM}_{\mathrm{TG}}$ participants had clinically significant scores in Depression scale and $45 \%$ had it in the Work Interference scale, versus only $4 \%$ and $8 \%$, respectively, in the $\mathrm{RA}_{\mathrm{TG}}$.

\section{Discussion}

The first main goal of this study was to identify if there are distinct clinical profiles in FM and RA groups of patients, and then consider the more typical patients of each pathology to further explore their broader

Table 5

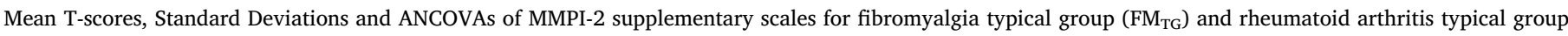
$\left(\mathrm{RA}_{\mathrm{TG}}\right)$.

\begin{tabular}{|c|c|c|c|c|c|c|c|c|c|c|c|}
\hline & \multicolumn{2}{|l|}{$\mathrm{FM}_{\mathrm{TG}}$} & \multicolumn{2}{|l|}{$\mathrm{RA}_{\mathrm{TG}}$} & \multirow[t]{2}{*}{$\mathrm{F}$} & \multirow[t]{2}{*}{$\eta^{2}$} & \multirow[t]{2}{*}{$\mathrm{p}$} & \multicolumn{2}{|c|}{$\mathrm{FM}_{\mathrm{TG}}(\%)$} & \multicolumn{2}{|c|}{$\mathrm{RA}_{\mathrm{TG}}(\%)$} \\
\hline & M & SD & M & SD & & & & $\mathrm{T} \geq 65$ & $\mathrm{~T} \leq 40$ & $\mathrm{~T} \geq 65$ & $\mathrm{~T} \leq 40$ \\
\hline A & 59.33 & 7.22 & 50.33 & 6.46 & 25.37 & 0.320 & .000 & 21 & 0 & 4 & 4 \\
\hline $\mathrm{R}$ & 60.30 & 9.53 & 55.50 & 10.45 & 1.57 & 0.028 & .216 & 33 & 0 & 25 & 4 \\
\hline Es & 31.73 & 2.97 & 41.88 & 8.21 & 35.37 & 0.396 & .000 & 0 & 97 & 0 & 38 \\
\hline Mt & 67.85 & 6.61 & 52.83 & 6.59 & 66.25 & 0.551 & .000 & 58 & 0 & 4 & 0 \\
\hline PK & 64.88 & 8.93 & 50.50 & 6.73 & 35.04 & 0.394 & .000 & 42 & 0 & 0 & 8 \\
\hline MDS & 63.42 & 9.56 & 54.38 & 9.63 & 10.91 & 0.168 & .002 & 30 & 0 & 13 & 0 \\
\hline Ho & 58.15 & 8.49 & 54.25 & 7.68 & 3.14 & 0.055 & .082 & 21 & 6 & 8 & 0 \\
\hline $\mathrm{O}-\mathrm{H}$ & 57.33 & 7.97 & 49.00 & 9.19 & 7.09 & 0.116 & .010 & 21 & 0 & 8 & 17 \\
\hline GM & 41.48 & 7.09 & 52.33 & 9.97 & 29.91 & 0.356 & .000 & 0 & 45 & 4 & 13 \\
\hline
\end{tabular}

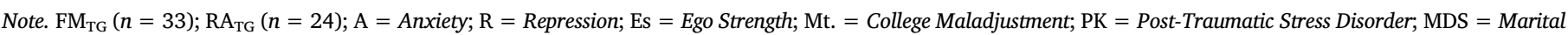
Distress; Ho = Hostility; O-H = Over-Controlled Hostility; GM = Gender Role-Masculine. 
Table 6

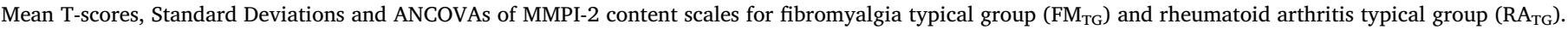

\begin{tabular}{|c|c|c|c|c|c|c|c|c|c|c|c|}
\hline & \multicolumn{2}{|l|}{$\mathrm{FM}_{\mathrm{TG}}$} & \multicolumn{2}{|l|}{$\mathrm{RA}_{\mathrm{TG}}$} & \multirow[t]{2}{*}{$\mathrm{F}$} & \multirow[t]{2}{*}{$\eta^{2}$} & \multirow[t]{2}{*}{$\mathrm{p}$} & \multicolumn{2}{|c|}{$\mathrm{FM}_{\mathrm{TG}}(\%)$} & \multicolumn{2}{|c|}{$\mathrm{RA}_{\mathrm{TG}}(\%)$} \\
\hline & $\mathrm{M}$ & SD & M & SD & & & & $\mathrm{T} \geq 65$ & $\mathrm{~T} \leq 40$ & $\mathrm{~T} \geq 65$ & $\mathrm{~T} \leq 40$ \\
\hline ANX & 66.33 & 9.84 & 50.71 & 6.55 & 16.96 & 0.242 & .000 & 58 & 0 & 0 & 8 \\
\hline FRS & 60.03 & 13.81 & 52.38 & 12.06 & 1.54 & 0.028 & .220 & 30 & 6 & 13 & 17 \\
\hline OBS & 54.64 & 8.80 & 50.71 & 6.79 & 1.10 & 0.020 & .299 & 18 & 0 & 8 & 0 \\
\hline DEP & 63.21 & 8.12 & 52.67 & 4.91 & 23.57 & 0.308 & .000 & 48 & 0 & 4 & 0 \\
\hline HEA & 79.79 & 9.46 & 58.13 & 7.68 & 23.20 & 0.305 & .000 & 94 & 0 & 21 & 0 \\
\hline BIZ & 57.58 & 9.55 & 52.67 & 7.92 & 4.53 & 0.079 & .038 & 15 & 6 & 8 & 8 \\
\hline ANG & 54.12 & 9.42 & 52.92 & 11.06 & 2.78 & 0.050 & .101 & 12 & 6 & 21 & 17 \\
\hline LSE & 55.61 & 8.02 & 49.13 & 8.31 & 9.34 & 0.150 & .004 & 15 & 3 & 8 & 13 \\
\hline FAM & 55.39 & 11.26 & 47.08 & 9.22 & 7.78 & 0.128 & .007 & 18 & 3 & 4 & 25 \\
\hline WRK & 62.55 & 10.01 & 51.46 & 7.25 & 20.75 & 0.281 & .000 & 45 & 0 & 8 & 0 \\
\hline TRT & 58.45 & 9.99 & 53.38 & 8.15 & 3.58 & 0.063 & .064 & 21 & 0 & 4 & 8 \\
\hline
\end{tabular}

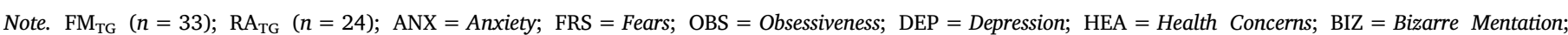
ANG $=$ Anger $;$ LSE $=$ Low Self-Esteem; FAM $=$ Family Problems $;$ WRK $=$ Work Interference $;$ TRT $=$ Negative Treatment Indicators

psychological characterization. In this first step of our analysis, the FM group had significantly higher mean scores on six of the eight clinical scales, and is relevant that the AR group did not have any clinically significant elevation, even on the neurotic triad scales, in which it is predictable that chronic pain patients have significant elevations (Keller \& Butcher, 1991). FM group, on the contrary, has significant elevations on five scales, the neurotic triad scales, Psychasthenia and Schizophrenia, which refer to more severe psychopathology.

It has been showed that in FM patients with a high psychological disturbance profile, one or both of these scales often appear elevated (Ahles et al., 1984; Payne et al., 1982; Pérez-Pareja et al., 2010; PorterMoffitt et al., 2006). Thereby, these differences between FM and RA patients are in line with the literature (Ardiç \& Toraman, 2002; Leavitt \& Katz, 1989; Wolfe et al., 1984) and led us to a further exploration of these major differences. A cluster analysis of the basic clinical profiles obtained two clusters of scales that identified the typical patients of each pathology, and the $\mathrm{FM}_{\mathrm{TG}}$ had clinically significant scores on five of the eight clinical scales, and higher than RA scores on seven of them, while the $\mathrm{RA}_{\mathrm{TG}}$ had no significant elevation. Given the sample dimension and the possibility of overfitting that must be considered, these results should be seen as exploratory endeavors, which should be further explored in the future.

Subsequently, our second main goal was to assess the differences between the $\mathrm{FM}_{\mathrm{TG}}$ and $\mathrm{RA}_{\mathrm{TG}}$ more broadly, in the personality psychopathology, content, and supplementary scales of the MMPI-2. On the personality psychopathology scales, the fact that the $\mathrm{FM}_{\mathrm{TG}}$ had significantly higher levels of Negative Emotionality/Neuroticism is in line with the literature. Neuroticism, as one of the five normative personality dimensions and measured with, among others, the Revised NEO Personality Inventory (Costa \& McCrae, 1992), has been found higher in FM than in AR (Besteiro et al., 2008; Bucourt et al., 2017; Walker et al., 1997), and Neuroticism here measured as a personality psychopathology scale may be considered an extreme variant of the former (Egger, De Mey, Derksen, \& van der Staak, 2003; Trull, Useda, Costa, \& McCrae, 1995). Although the mean value is not clinically significant, when we look at the percentage of patients in $\mathrm{FM}_{\mathrm{TG}}$ with clinically significant elevations in Negative Emotionality/Neuroticism, we may see that almost half of the group had it.

On the set of supplementary scales, $\mathrm{FM}_{\mathrm{TG}}$ has significantly higher levels on scales that involve ineffectiveness, pessimism, low self-esteem, intense emotional distress, dissatisfaction with marriage or romantic relationship and defensiveness and emotional overcontrol. On the other hand, $\mathrm{FM}_{\mathrm{TG}}$ has significantly lower levels on scales that involve general adjustment, resources for coping with life demands, power in face to face personal situations and self-confidence. The emotional distress and maladjustment are significantly high, and self-confidence and self-esteem are significantly low in this group.
Pertaining to College Maladjustment, this scale scores have been found to be associated with increased stress and lowered social and general adjustment (Stewart \& Cairns, 2002), and may also indicate, on a global level, that the client has a history of inadequate coping and functioning. It assesses maladjustment in a manner similar to that of the Anxiety and Ego Strength scales, and is strongly related to the clinical Schizophrenia scale, due to aspects tapped by this scale as depression and hopelessness, feeling that life is a strain, having difficulty coping and worrying excessively (Barthlow, Graham, Ben-Porath, \& McNulty, 2004). So, College Maladjustment scale being clinically elevated in the $\mathrm{FM}_{\mathrm{TG}}$ is congruent with also clinically significant Schizophrenia and Ego Strength scales.

Regarding Post-Traumatic Stress Disorder scale, it is suggested that this scale is more a measure of general psychopathology, maladjustment and dysphoric feelings than it is a measure of post-traumatic stress disorder (PTSD) (Moody \& Kish, 1989). In a sample of women with somatization disorder, without any reported exposure to a life-threatening event, more than half had significant elevations on this scale and, as it was quite unlikely that they would have PTSD, the authors state that this scale, in women with somatization disorder, appears to be measuring features not specific to having a traumatically caused psychiatric condition (Wetzel et al., 2000). Higher Post-Traumatic Stress Disorder scale scores has been associated with higher general level of emotional and psychological distress scores and lower ego strength scores (Moody \& Kish, 1989) and higher neuroticism and introversion/ low positive emotionality (Haisch \& Meyers, 2004), which is in line with our results in the $\mathrm{FM}_{\mathrm{TG}}$. As these authors claim, individuals with higher Post-Traumatic Stress Disorder scale scores are best described as being at higher risk of PTSD, and it may be that very high scores are indicative of PTSD, but more moderate elevations reflect general distress (Graham, 2012). In any case, it is well known that patients with comorbid chronic pain and PTSD report more severe pain and life interference (Turk \& Okifuji, 1996), more intense pain and affective distress (Geisser, Roth, Bachman, \& Eckert, 1996) and greater disability (Sherman, Turk, \& Okifuji, 2000) than pain patients without trauma or PTSD.

With regard to Marital Distress scale, it has been known that, in pain samples, marital discord and spouse responses to pain are positively related to pain intensity and physical disability, and that marital dissatisfaction and negative spouse responses are also associated with elevated depressive symptoms (Cano, Weisberg, \& Gallagher, 2000; Kerns, Haythornthwaite, Southwick, \& Giller Jr., 1990; Turk, Kerns, \& Rosenberg, 1992). In a study with FM patients and their co-residing partners, these partners, on average, rated patient fatigue significantly lower than patients (Lyons, Jones, Bennett, Hiatt, \& Sayer, 2013), and in the same line, with RA patients and their spouses, there were considerable differences in estimations of the patient's functional 
disabilities, and these differences were associated with the patient's poorer mental health status (Riemsma, Taal, \& Rasker, 2000). So, it seems that it is difficult for the chronic pain patient partner to correctly estimate the patient pain and disability, and this seems to be worse in the case of FM, as invisibility causes difficulty for those who interact with patients, namely, the spouse (Söderberg et al., 2003).

In studies with AR patients and their partners, both patients and spouses were generally satisfied with their marriages (Bermas, Tucker, Winkelman, \& Katz, 2000) and 75\% of the respondents had scores reflecting normal marital satisfaction (van Lankveld, Ruiterkamp, Näring, \& de Rooij, 2004). We found no study comparing marital satisfaction in FM and AR patients, but in a study comparing FM and osteoarthritis (OA) patients, although FM and OA partners both had comparable levels of burden, increased partner burden was associated with lower levels of partner support in the FM group only. Patients with FM had higher levels of illness uncertainty, and it negatively influenced their dyadic relationship, contrarily to the OA patients, and the authors stated that the obviousness of disability of OA patients, combined with the well understood etiology of OA, appear to protect these patients and their partner's relation (Reich et al., 2006). Finally, it seems plausible that it is this pattern of high distress and psychological turmoil in the $\mathrm{FM}_{\mathrm{TG}}$ to contribute to the marital distress, as psychological distress and social support are more important in explaining marital satisfaction than the patient's disease status (van Lankveld et al., 2004).

Pertaining to Ego Strength and Gender Role-Masculine scales, in the context of disease, headaches patients scored lower than healthy controls on Ego Strength scale (Sances et al., 2010) and low ego strength, along with introverted hostility, played a crucial role in the psychiatric symptom formation in multiple sclerosis patients (Hyphantis et al., 2008). In what respects to Gender Role-Masculine scale, higher scores are associated with less psychopathology (Castlebury \& Durham, 1997) and more psychological well-being, and higher ego strength and self-esteem (Woo \& Oei, 2006). So, the lower levels of the $\mathrm{FM}_{\mathrm{TG}}$ in this triad of scales reflect more insecurity and less assertiveness in these patients.

Pertaining to Over-Controlled Hostility, Megargee, Cook, and Mendelsohn (1967) suggested that persons with significantly high scores on this scale would have low assertiveness and a high level of inhibition that prevents them from regularly exhibiting their anger, and occasionally may act out with extreme aggressiveness. We hypothesize that the higher over-controlled hostility in the $\mathrm{FM}_{\mathrm{TG}}$, although not significantly high, is combined with a set of features that, although not clinically significant by themselves, may have a relevant role in the FM functioning, in association with each other and with the clinically significant ones, as low ego strength and masculine gender role. We have not found any study discussing over-controlled hostility in chronic pain patients but, as there is evidence of a close conceptual relation between anger and hostility (Forgays, Forgays, \& Spielberger, 1997), and we think it is possible to compare over-controlled hostility with anger control and anger-in, two dimensions assessed by the State-Trait Anger Expression Inventory (Spielberger, 1988).

Anger-in or anger suppression is defined as the inhibition of anger and it refers to the frequency with which angry feelings are experienced but not expressed (Spielberger, 1999), and it has been associated with conflict avoidance, guilt, irritability, rumination, depressive symptoms, and decreased life satisfaction (Gross \& John, 2003; Martin \& Dahlen, 2007) and with a stronger perception of lacking social support (Palfai \& Hart, 1997). Anger control is similar to anger-in or anger suppression, in that it involves not displaying anger to others and so not risking relational harmony (Yamaguchi, Kim, Oshio, \& Akutsu, 2017). FM patients showed higher scores of anger-in compared to RA and when the severity of pain was controlled, trait-anger and anger-out were higher in the RA group, whereas anger in was still higher in the FM group (Sayar et al., 2004), and this is similar to our finding that RA has significantly lower over-controlled hostility. In a FM sample, a general tendency to inhibit anger was associated with more pain (van Middendorp et al., 2010). Thereby, the combination of higher over- controlled hostility and, although non-significant, an absolute higher value of hostility and of anger, may constitute a pattern of low assertiveness and contained emotional expression that may undermine these patients.

Pertaining to the content scales, the $\mathrm{FM}_{\mathrm{TG}}$ had significantly higher levels on scales that involve tension, pessimism, depressive thoughts and feeling unsupported by others, worries about health and multiple somatic complaints, tendency to paranoid ideation and low frustration tolerance, passiveness and lack of self-confidence, resentment with family members, sensitivity to criticism and inability to tolerate stress, negative attitudes toward coworkers, lack of achievement orientation, feeling misunderstood and overwhelmed by adversities (Graham, 2012). The tension, worries, difficulty in making decisions, pessimism, and presentation of multiple somatic complaints are clinically significant, and almost half of the FM patients have clinically significant depressive thoughts and sensitivity to criticism and negative attitudes toward coworkers.

Although the Health Concerns scale is normally elevated in chronic pain patients (Keller \& Butcher, 1991; Slesinger, Archer, \& Duane, 2002), it goes beyond physical concerns clearly associated with the health problems, and better reflects the psychological representation of health problems. In a sample of non-chronic pain, victims of work bullying, the group with the lowest exposure specific negative actions had a more disturbed MMPI-2 clinical profile, and significantly higher anxiety, depression and health concerns, showing this scale is associated with psychological suffering (Matthiesen \& Einarsen, 2001).

The higher level on the Family Problems scale may be related to the also higher Marital Distress scale, as they both tap feelings of being misunderstood, resentment, feeling lack of love and affection both in the marriage and in the larger family. The only study we know comparing family features in FM and RA patients showed that the families of FM patients were no less cohesive or higher in conflict than RA families, contrary to what the authors had anticipated (Nicassio \& Radojevic, 1993). Kool et al. (2010) found that patients with FM experienced significantly more lack of understanding, denying and patronizing from their family, spouses, medical professionals, colleagues and social services than did patients with RA. Lack of mutual understanding is a common feeling in these women, from their closest family members and from other relatives (Juuso et al., 2014).

Finally, the Work Interference scale refers to a wide variety of attitudes and behaviors that are likely to contribute to poor work performance, as low self-confidence, poor concentration, obsessiveness, tension, indecisiveness, not having strong achievement orientation and possibly having negative attitude toward coworkers (Graham, 2012). So, it encompasses a whole set of features beyond work environment directly. Wentz, Lindberg, and Hallberg (2004) showed that psychological stress at work among women with FM increases their sense of lack of control. Several studies report decreased work ability in FM (Henriksson, Liedberg, \& Gerdle, 2005) and that the symptoms impair the performance, there is a physical and mental overload and superiors or colleagues do not understand and respect these consequences of FM (Arnold et al., 2008; Juuso et al., 2014; Mannerkorpi \& Gard, 2012; Sallinen, Kukkurainen, Peltokallio, \& Mikkelsson, 2010).

In sum, relational uncertainty is a main theme found in the experience of FM patients, pertaining to interactions with everybody in the patient's life: family, friends, doctors, colleagues and even support groups; all these interactions are seen as unpredictable and, for many participants, there was an undercurrent of defensiveness running through all interactions (Dennis, Larkin, \& Derbyshire, 2013). As these authors stated, it is important that participants who reported negative experiences, tended to report them in multiple interactions, suggesting individual differences in interpretations and expectations. The harmful impact of negative social interactions on pain has been demonstrated (Eisenberger \& Lieberman, 2004), as neural systems underlying the experiences of physical pain and social rejection overlap, suggesting that invalidation experiences may amplify pain, but pain sensitivity 
may also increase the invalidation experiences (Eisenberger, Jarcho, Lieberman, \& Naliboff, 2006). This is very important to consider when we interpret the higher pain reported by our $\mathrm{FM}_{\mathrm{TG}}$, compared to the $\mathrm{RA}_{\mathrm{TG}}$, as $\mathrm{FM}$ combines more psychopathology and distress linked to feelings of social alienation as expressed by Schizophrenia clinical scale, and high intensity of reported pain.

In conclusion, recalling the main goal of this work, we wanted to investigate if the differences presented by FM patients in comparison with healthy controls in psychopathology (Novo et al., 2017) would remain when compared with a chronic medically explained pain group. In effect, these differences remained, showing the specificity of FM, mainly characterized by much higher psychological and emotional distress and difficulties in coping and dealing with life and others. The symptomology expressed through the clinical scales is much higher than RA and clinically significant; in what concerns the personality psychopathology, the mean pattern is globally within the normal range, but there is a considerable percentage of patients with significantly high levels of neuroticism, showing negative affectivity, guilt, self-criticism and focus on the negative side of things.

Finally, the time these women spend between the onset of their FM symptoms and having a diagnosis shows some interesting associations with personality and psychopathology features, which all share some common meaning; this pain without diagnosis is related to more focus in the body and bodily sensations, more repression and constraint, and less ego strength. It is plausible that the time before a diagnosis is given has a high negative impact in the patients' psychological and social adjustment, because the uncertainty affects them and the way they feel others perceive them, leading to a tendency to withdraw verbalization of emotions (Herbette \& Rimé, 2004). Therefore, this longer period in the FM group, where the suffering "has no name" may contribute to more inhibition and growing psychological vulnerability in these women, possibly acting to exacerbate the whole suffering beyond the physical symptoms, and then being a perpetuating factor. We acknowledge that albeit this was not the focus of this study, and the measurement of time between the onset of pain and the diagnosis cannot be sufficiently precise in our sample, the impact of stigma or prolonged periods of experiencing pain without diagnosis likely play a role that should be adequately addressed in future research.

This study is, to our knowledge, the only study exploring the differences between FM and RA patients (or other chronic pain patients) in most of the scales of the whole set of MMPI-2 personality psychopathology, supplementary and content scales. It allowed the identification of a set of features that have shown to be very relevant in distinguishing a more psychopathological group from a less one, in association with the clinical scales, both in the comparison between $\mathrm{FM}_{\mathrm{TG}}$ and $\mathrm{RA}_{\mathrm{TG}}$. Thereby, we think the potential of these set of scales in this field has been highlighted, and MMPI-2 gives us a broad personality and psychopathology analysis that may be relevant in the individual psychological assessment of FM patients. Moreover, we have a relatively homogeneous sample of adult and middle-aged women, without psychiatric diagnosis and psychological treatment, what makes it a "normative" sample of female chronic pain patients (although it obviously does not mean that the sample is completely free from a psychiatric disorder, what cannot be guaranteed).

The sample dimension is a limitation of this study, and it may have limited the significance of differences found between the groups. On the other hand, given the sample size, there is a risk of overfitting, concerning the groups extracted from cluster analysis, and for this reason these results must be regarded as exploratory and should be replicated with larger and representative samples. All the sample was recruited through associations of patients, and these patients may have distinct features from other patients in the community; in any case, the fact that both FM and RA groups were in the same condition reduces this potential issue. Finally, the cross-sectional design of this study does not allow considerations about causality.

In terms of intervention, this study results enhance the idea that is not possible to diagnose and adequately treat FM patients without attending the psychological aspects associated with this syndrome. The $\mathrm{FM}_{\mathrm{TG}}$ seem to have a psychological pattern that goes beyond the impact of chronic pain. They seem to be repressing their difficulties and problems, in an ineffective way, as despite this inhibition they still manifest clinically significant levels of anxiety and distress. Their pattern of low assertiveness and affirmation increases their vulnerability, and a clinical intervention should enhance the externalizing of their problems, emotions and needs. Three studies with FM patients have shown positive outcomes of written emotional disclosure or expressive writing, as a way of accessing previously avoided negative memories and emotions in writing (Broderick, Junghaenel, \& Schwartz, 2005; Gillis, Lumley, Mosley-Williams, Leisen, \& Roehrs, 2006; Junghaenel, Schwartz, \& Broderick, 2008). Recently, Lumley et al. (2017) developed an emotional awareness and expression therapy with FM patients, and this intervention targeting emotional awareness and expression related to psychosocial adversity and emotional conflict, had promising results.

We suggest an intervention that focuses not only on the processing of stressful experiences, but most of all on the feelings of resentment and potential hostility they may be having toward significant others, and not expressing with worry about rejection, and perhaps, in some way, turning against themselves, what enhances their passiveness and lack of ego strength. In parallel, as suggested by Middentorp et al. (2010), the patients could be taught to respond to anger in adaptive ways with healthy expression, including appropriate assertion or sharing of feelings with appropriate targets.

\section{Funding}

This work was supported by grants from the Portuguese Foundation for Science and Technology (SFRH/BD/44141/2008).

\section{Declarations of interest}

None.

\section{References}

Ahles, T. A., Yunus, M. B., Riley, S. D., Bradley, J. M., \& Masi, A. T. (1984). Psychological factors associated with primary fibromyalgia syndrome. Arthritis and Rheumatism, 27, 1101-1106.

Applegate, K. L., Keefe, F. J., Siegler, I. C., Bradley, L. A., McKee, D. C., Cooper, K. S., \& Riordan, P. (2005). Does personality at college entry predict number of reported pain conditions at mid-life? A longitudinal study. The Journal of Pain, 6(2), 92-97. https:// doi.org/10.1016/j.jpain.2004.11.001.

Arbisi, P. A., \& Butcher, J. N. (2004). Relationship between personality and health symptoms: Use of the MMPI-2 in medical assessments. International Journal of Clinical and Health Psychology, 4, 571-595.

Ardiç, F., \& Toraman, F. (2002). Psychological dimensions of pain in patients with rheumatoid arthritis, fibromyalgia syndrome, and chronic low back pain. Journal of Musculoskeletal Pain, 10, 19-29. https://doi.org/10.1300/J094v10n04_03.

Arnold, L. M., Crofford, L. J., Mease, P. J., Burgess, S. M., Palmer, S. C., Abetz, L., \& Martin, S. A. (2008). Patient perspectives on the impact of fibromyalgia. Patient Education and Counseling, 73, 114-120.

Barthlow, D. L., Graham, J. R., Ben-Porath, Y. S., \& McNulty, J. L. (2004). Construct validity of the MMPI-2 College Maladjustment (Mt) Scale. Assessment, 11, 251-262. https://doi.org/10.1177/1073191104268317.

Bellato, E., Marini, E., Castoldi, F., Barbasetti, N., Mattei, L., Bonasia, D. E., \& Blonna, D. (2012). Fibromyalgia syndrome: Etiology, pathogenesis, diagnosis, and treatment. Pain Research and Treatment, 426130. https://doi.org/10.1155/2012/426130.

Bermas, B. L., Tucker, J. S., Winkelman, D. K., \& Katz, J. N. (2000). Marital satisfaction in couples with rheumatoid arthritis. Arthritis Care and Research, 13, 149-155.

Besteiro, J., Alvarez, M., Lemos, S., Muñiz, J., Costas, C., \& Weruaga, A. (2008) Dimensiones de personalidad, sentido de coherencia y salud percibida en pacientes con un síndrome fíbromiálgico. International Journal of Clinical and Health Psychology, 8, 411-427.

Bigos, S. J., Battie, M. C., Spengler, D. M., Fisher, L. D., Fordyce, W. E., Hansson, T. H., Wortley, M. D. (1991). A prospective study of work perceptions and psychosocial factors affecting the report of back injury. Spine, 16(1), 1-6.

Broderick, J. E., Junghaenel, D. U., \& Schwartz, J. E. (2005). Written emotional expression produces health benefits in fibromyalgia patients. Psychosomatic Medicine, 67, 326-334. https://doi.org/10.1097/01.psy.0000156933.04566.bd.

Bucourt, E., Martaillé, V., Mulleman, D., Goupille, P., Joncker-Vannier, I., Huttenberger, B., ... Courtois, R. (2017). Comparison of the Big Five personality traits in 
fibromyalgia and other rheumatic diseases. Joint, Bone, Spine: Revue du Rhumatisme, 84, 203-220. https://doi.org/10.1016/j.jbspin.2016.03.006.

Butcher, J. N., Dahlstrom, W. G., Graham, J. R., Tellegen, A., \& Kaemmer, B. (1989). The Minnesota Multiphasic Personality Inventory-2 (MMPI-2): Manual for administration and scoring. Minneapolis, MN: University of Minnesota Press.

Cano, A., Weisberg, J., \& Gallagher, M. (2000). Marital satisfaction and pain severity mediate the association between negative spouse responses to pain and depressive symptoms in a chronic pain patient sample. Pain Medicine, 1, 35-43. https://doi.org/ 10.1046/j.1526-4637.2000.99100.x.

Castlebury, F. D., \& Durham, T. W. (1997). The MMPI-2 GM and GF scales as measures of psychological well-being. Journal of Clinical Psychology, 53, 879-893.

Charles, S. T., Gatz, M., Kato, K., \& Pedersen, N. L. (2008). Physical health 25 years later: The predictive ability of neuroticism. Health Psychology, 27(3), 369-378. https://doi. org/10.1037/0278-6133.27.3.369.

Costa, P. T., \& McCrae, R. R. (1992). Revised NEO Personality Inventory (NEO-PI-R) and NEO Five-Factor Inventory (NEO-FFI): Professional manual. Odessa, FL: Psychologica Assessment Resources.

Dennis, N. L., Larkin, M., \& Derbyshire, S. W. (2013). 'A giant mess' - Making sense of complexity in the accounts of people with fibromyalgia. British Journal of Health Psychology, 18, 763-781. https://doi.org/10.1111/bjhp.12020.

Diatchenko, L., Nackley, A. G., Slade, G. D., Fillingim, R. B., \& Maixner, W. (2006). Idiopathic pain disorders - Pathways of vulnerability. Pain, 123, 226-230. https:// doi.org/10.1016/j.pain.2006.04.015.

Edwards, E. L., Holmes, C. B., \& Carvajal, H. H. (1998). Oral and booklet presentation of MMPI-2. Journal of Clinical Psychology, 54, 593-596. https://doi.org/10.1002/(SICI) 1097-4679.

Egger, J. I., De Mey, H. R. Derksen, J. J., \& van der Staak, C. P. (2003). Cross-cultura replication of the Five-Factor Model and comparison of the NEO-PI-R and MMPI-2 PSY-5 scales in a Dutch psychiatric sample. Psychological Assessment, 15, 81-88.

Eisenberger, N. I., Jarcho, J. M., Lieberman, M. D., \& Naliboff, B. D. (2006). An experimental study of shared sensitivity to physical pain and social rejection. Pain, 126, 132-138. https://doi.org/10.1016/j.pain.2006.06.024.

Eisenberger, N. I., \& Lieberman, M. D. (2004). Why rejection hurts: A common neural alarm system for physical and social pain. Trends in Cognitive Science, 8, 294-300. https://doi.org/10.1016/j.tics.2004.05.010.

Fitzcharles, M. A., \& Yunus, M. B. (2012). The clinical concept of fibromyalgia as a changing paradigm in the past 20 years. Pain Research and Treatment, 2012, 184835. https://doi.org/10.1155/2012/184835.

Forgays, D. G., Forgays, D. K., \& Spielberger, C. D. (1997). Factor structure of the StateTrait Anger Expression Inventory. Journal of Personality Assessment, 69, 497-507. https://doi.org/10.1207/s15327752jpa6903 5.

Geisser, M. E., Roth, R. S., Bachman, J. E., \& Eckert, T. A. (1996). The relationship between symptoms of post-traumatic stress disorder and pain, affective disturbance and disability among patients with accident and non-accident related pain. Pain, 66, 207-214.

Gillis, M. E., Lumley, M. A., Mosley-Williams, A., Leisen, J. C., \& Roehrs, T. (2006). The health effects of at-home written emotional disclosure in fibromyalgia: A randomized trial. Annals of Behavioral Medicine, 32, 135-146. https://doi.org/10.1207/ s15324796abm3202_11.

Gonzalez, B. (2013). Aspectos psicológicos da fibromialgia: Personalidade e história de vida [Psychological aspects of fibromyalgia: Personality and life story] (Doctoral dissertation). Retrieved from http://repositorio.ul.pt/bitstream/10451/11052/1/ulsd066203_td_ Barbara_Gonzalez.pdf.

Graham, J. R. (2012). MMPI-2: Assessing personality and psychopathology (5th ed.). New York, NY: Oxford University Press.

Greene, R. L. (2000). The MMPI-2: An interpretive manual (2nd ed.). Needham Heights, MA: Allyn \& Bacon.

Gross, J. J., \& John, O. P. (2003). Individual differences in two emotion regulation processes: Implications for affect, relationships, and well-being. Journal of Personality and Social Psychology, 85, 348-362.

Haisch, D. C., \& Meyers, L. S. (2004). MMPI-2 assessed posttraumatic stress disorder related to job stress, coping, and personality in police agencies. Stress and Health, 20 , 223-229. https://doi.org/10.1002/smi.1020.

Hansen, F. R., Biering-Sørensen, F., \& Schroll, M. (1995). Minnesota Multiphasic Personality Inventory profiles in persons with or without low back pain. A 20-year follow-up study. Spine, 20, 2716-2720.

Hartrick, C. T., Kovan, J. P., \& Shapiro, S. (2003). The numerical rating scale for clinical pain measurement: A ratio measure? Pain Practice, 3, 310-316.

Hassett, A. L., Cone, J. D., Patella, S. J., \& Sigal, L. H. (2000). The role of catastrophizing in the pain and depression of women with fibromyalgia syndrome. Arthritis and Rheumatism, 43, 2493-2500. https://doi.org/10.1002/1529-0131(200011) 43:11 < 2493::AID-ANR17> 3.0.CO;2-W.

Henriksson, C., Liedberg, G., \& Gerdle, B. (2005). Women with fibromyalgia: Work and rehabilitation. Disability and Rehabilitation, 27, 685-695. https://doi.org/10.1080/ 09638280400009089.

Herbette, G., \& Rimé, B. (2004). Verbalization of emotion in chronic pain patients and their psychological adjustment. Journal of Health Psychology, 9, 661-676. https://doi org/10.1177/1359105304045378.

Hyphantis, T. N., Christou, K., Kontoudaki, S., Mantas, C., Papamichael, G., Goulia, P., .. Mavreas, V. (2008). Disability status, disease parameters, defense styles, and ego strength associated with psychiatric complications of multiple sclerosis. International Journal of Psychiatry in Medicine, 38, 307-327. https://doi.org/10.2190/PM.38.3.g.

Junghaenel, D. U., Schwartz, J. E., \& Broderick, J. E. (2008). Differential efficacy of written emotional disclosure for subgroups of fibromyalgia patients. British Journal of Health Psychology, 13, 57-60. https://doi.org/10.1348/135910707X251162.

Juuso, P., Skär, L., Olsson, M. \& Söderberg, S. (2014). Meanings of being received and met by others as experienced by women with fibromyalgia. Qualitative Health Research, 24, 1381-1390. https://doi.org/10.1177/1049732314547540.

Keller, L. S., \& Butcher, J. N. (1991). Assessment of chronic pain patients with the MMPI-2. Minneapolis: University of Minnesota Press.

Kerns, R. D., Haythornthwaite, J., Southwick, S., \& Giller, E. L., Jr. (1990). The role of marital interaction in chronic pain and depressive symptom severity. Journal of Psychosomatic Research, 34, 401-408.

Kool, M. B., van Middendorp, H., Lumley, M. A., Schenk, Y., Jacobs, J. W., Bijlsma, J. W., \& Geenen, R. (2010). Lack of understanding in fibromyalgia and rheumatoid arthritis: The Illness Invalidation Inventory. Annals of the Rheumatic Diseases, 69, 1990-1995. https://doi.org/10.1136/ard.2009.123224.

Leavitt, F., \& Katz, R. S. (1989). Is the MMPI invalid for assessing psychological disturbance in pain related organic conditions? The Journal of Rheumatology, 16, 521-526.

Lumley, M. A., Schubiner, H., Lockhart, N. A., Kidwell, K. M., Harte, S. E., Clauw, D. J., \& Williams, D. A. (2017). Emotional awareness and expression therapy, cognitive behavioral therapy, and education for fibromyalgia: A cluster-randomized controlled trial. Pain, 158, 2354-2363. https://doi.org/10.1097/j.pain.0000000000001036.

Lyons, K. S., Jones, K. D., Bennett, R. M., Hiatt, S. O., \& Sayer, A. G. (2013). Couple perceptions of fibromyalgia symptoms: The role of communication. Pain, 154 2417-2426. https://doi.org/10.1016/j.pain.2013.07.018.

Malin, K., \& Littlejohn, G. O. (2012). Personality and fibromyalgia syndrome. The Open Rheumatology Journal, 6, 273-285. https://doi.org/10.2174/ 1874312901206010273.

Mannerkorpi, K., \& Gard, G. (2012). Hinders for continued work among persons with fibromyalgia. BMC Musculoskeletal Disorders, 13, 96. https://doi.org/10.1186/14712474-13-96.

Martin, R. C., \& Dahlen, E. R. (2007). Anger response styles and reaction to provocation. Personality and Individual Differences, 43, 2083-2094. https://doi.org/10.1016/j.paid. 2007.06.022.

Matthiesen, S. B., \& Einarsen, S. (2001). MMPI-2 configurations among victims of bullying at work. European Journal of Work and Organizational Psychology, 10, 467-484. https://doi.org/10.1080/13594320143000753.

McBeth, J., Macfarlane, G. J., Benjamin, S., \& Silman, A. J. (2001). Features of somatization predict the onset of chronic widespread pain: Results of a large populationbased study. Arthritis and Rheumatism, 44, 940-946. https://doi.org/10.1002/1529. 0131(200104)44:4<940::AID-ANR151>3.0.CO*2-S.

Mease, P. (2005). Fibromyalgia syndrome: Review of clinical presentation, pathogenesis, outcome measures, and treatment. The Journal of Rheumatology. Supplement, 75, 6-21.

Megargee, E. I., Cook, P. E., \& Mendelsohn, G. A. (1967). Development and validation of an MMPI scale of assaultiveness in overcontrolled individuals. Journal of Abnormal Psychology, 72, 519-528. https://doi.org/10.1037/h0025242.

Moody, D. R., \& Kish, G. B. (1989). Clinical meaning of the Keane PTSD Scale. Journal of Clinical Psychology, 45, 542-554.

Naylor, B., Boag, S., \& Gustin, S. M. (2017). New evidence for a pain personality? A critical review of the last 120 years of pain and personality. Scandinavian Journal of Pain, 17, 58-67. https://doi.org/10.1016/j.sjpain.2017.07.011.

Nicassio, P. M., \& Radojevic, V. (1993). Models of family functioning and their contribution to patient outcomes in chronic pain. Motivation and Emotion, 17, 295-316. https://doi.org/10.1007/BF00992224.

Novo, R., Gonzalez, B., Peres, R., \& Aguiar, P. (2017). A meta-analysis of studies with the Minnesota Multiphasic Personality Inventory in fibromyalgia patients. Personality and Individual Differences, 116, 96-108. https://doi.org/10.1016/j.paid.2017.04.026.

Palfai, T. P., \& Hart, K. E. (1997). Anger coping styles and perceived social support. The Journal of Social Psychology, 137, 405-411. https://doi.org/10.1080/ 00224549709595455

Payne, T. C., Leavitt, F., Garron, D. C., Katz, R. S., Golden, H. E., Glickman, P. B., \& Vanderplate, C. (1982). Fibrositis and psychologic disturbance. Arthritis and Rheumatism, 25, 213-217. https://doi.org/10.1002/art.1780250216.

Pérez-Pareja, J., Sesé, A., González-Ordi, H., \& Palmer, A. (2010). Fibromyalgia and chronic pain: Are there discriminating patterns by using the Minnesota Multiphasic Personality Inventory-2 (MMPI-2)? International Journal of Clinical and Health Psychology, 10, 41-56.

Porter-Moffitt, S., Gatchel, R. J., Robinson, R. C., Deschner, M., Posamentier, M., Polatin, P., \& Lou, L. (2006). Biopsychosocial profiles of different pain diagnostic groups. The Journal of Pain, 7, 308-318. https://doi.org/10.1016/j.jpain.2005.12.003.

Reich, J. W., Olmsted, M. E., \& van Puymbroeck, C. M. (2006). Illness uncertainty, partner caregiver burden and support, and relationship satisfaction in fibromyalgia and osteoarthritis patients. Arthritis and Rheumatism, 55, 86-93. https://doi.org/10.1002/ art.21700.

Riemsma, R. P., Taal, E., \& Rasker, J. J. (2000). Perceptions about perceived functional disabilities and pain of people with rheumatoid arthritis: Differences between patients and their spouses and correlates with well-being. Arthritis Care and Research, 13, 255-261.

Salaffi, F., Sarzi-Puttini, P., Girolimetti, R., Atzeni, F., Gasparini, S., \& Grassi, W. (2009) Health-related quality of life in fibromyalgia patients: A comparison with rheumatoid arthritis patients and the general population using the SF-36 health survey. Clinical and Experimental Rheumatology, 27, 67-74.

Sallinen, M., Kukkurainen, M. L., Peltokallio, L., \& Mikkelsson, M. (2010). Women's narratives on experiences of work ability and functioning in fibromyalgia. Musculoskeletal Care, 8, 18-26. https://doi.org/10.1002/msc.162.

Sances, G., Galli, F., Anastasi, S., Ghiotto, N., De Giorgio, G., Guidetti, V., ... Nappi, G. (2010). Medication-overuse headache and personality: A controlled study by means of the MMPI-2. Headache, 50, 198-209. https://doi.org/10.1111/j.1526-4610.2009. 01593.x.

Sayar, K., Gulec, H., \& Topbas, M. (2004). Alexithymia and anger in patients with 
fibromyalgia. Clinical Rheumatology, 23, 441-448. https://doi.org/10.1007/ s10067004-0918-3.

Sherman, J. J., Turk, D. C., \& Okifuji, A. (2000). Prevalence and impact of posttraumatic stress disorder-like symptoms on patients with fibromyalgia syndrome. The Clinical Journal of Pain, 16, 127-134.

Silva, D., Novo, R., Prazeres, N., \& Pires, R. (2006). Inventário Multifásico de Personalidade de Minnesota (Adultos): Versão experimental portuguesa do MMPI-2 [Minnesota Multiphasic Personality Inventory (Adults): Portuguese experimental version of MMPI-2]. Lisboa: Centro de Investigação em Psicologia e Faculdade de Psicologia da Universidade de Lisboa.

Slesinger, D., Archer, R. P., \& Duane, W. (2002). MMPI-2 characteristics in a chronic pain population. Assessment, 9, 406-414. https://doi.org/10.1177/1073191102238153.

Söderberg, S., Strand, M., Haapala, M., \& Lundman, B. (2003). Living with a woman with fibromyalgia from the perspective of the husband. Journal of Advanced Nursing, 42, 143-150.

Spielberger, C. D. (1988). Manual for the State-Trait Anger Expression Inventory (STAXI). Odessa, FL: Psychological Assessment Resources.

Spielberger, C. D. (1999). State-Trait Anger Expression Inventory-2. Odessa, FL: Psychological Assessment Resources.

Stewart, D. W., \& Cairns, S. L. (2002). Objective versus subjective evaluation of student distress at intake: Considerations for counseling centers. Journal of College Student Development, 4, 386-394.

Trull, T. J., Useda, J. D., Costa, P. T., \& McCrae, R. R. (1995). Comparison of the MMPI-2 Personality Psychopathology Five (PSY-5), the NEO-PI, and the NEO-PI-R. Psychological Assessment, 7, 508-516.

Trygg, T., Lundberg, G., Rosenlund, E., Timpka, T., \& Gerdle, B. (2002). Personality characteristics of women with fibromyalgia and of women with chronic neck, shoulder or low back complaints in terms of Minnesota Multiphasic Personality Inventory and Defense Mechanism Technique Modified. Journal of Musculoskeletal Pain, 10, 33-55. https://doi.org/10.1300/J094v10n03 03.

Turk, D. C., Kerns, R. D., \& Rosenberg, R. (1992). Effects of marital interaction on chronic pain and disability: Examining the down side of social support. Rehabilitation Psychology, 37, 259-274.

Turk, D. C., \& Okifuji, A. (1996). Perception of traumatic onset, compensation status, and physical findings: Impact on pain severity, emotional distress, and disability in chronic pain patients. Journal of Behavioral Medicine, 19, 435-453. https://doi.org/ 10.1007/BF01857677.

Van Houdenhove, B., \& Egle, U. T. (2004). Fibromyalgia: A stress disorder? Piecing the biopsychosocial puzzle together. Psychotherapy and Psychosomatics, 73, 267-275. https://doi.org/10.1159/000078843.

Van Houdenhove, B., Luyten, P., \& Egle, U. T. (2009). Stress as a key concept in chronic widespread pain and fatigue disorders. Journal of Musculoskeletal Pain, 17, 390-399. https://doi.org/10.3109/10582450903284745.
Van Houdenhove, B., Neerinckx, E., Onghena, P., Lysens, R., \& Vertommen, H. (2001). Premorbid "overactive" lifestyle in chronic fatigue syndrome and fibromyalgia: An etiological factor or proof of good citizenship? Journal of Psychosomatic Research, 51, 571-576. https://doi.org/10.1016/S0022-3999(01)00247-1.

van Lankveld, W., Ruiterkamp, G., Näring, G., \& de Rooij, D. J. (2004). Marital and sexual satisfaction in patients with RA and their spouses. Scandinavian Journal of Rheumatology, 33, 405-408.

van Middendorp, H., Lumley, M. A., Moerbeek, M., Jacobs, J. W., Bijlsma, J. W., \& Geenen, R. (2010). Effects of anger and anger regulation styles on pain in daily life of women with fibromyalgia: A diary study. European Journal of Pain, 14, 176-182. https://doi.org/10.1016/j.ejpain.2009.03.007.

Walker, E. A., Keegan, D., Gardner, G., Sullivan, M., Bernstein, D., \& Katon, W. J. (1997) Psychosocial factors in fibromyalgia compared with rheumatoid arthritis: II. Sexual, physical, and emotional abuse and neglect. Psychosomatic Medicine, 59, 572-577.

Walker, J. G., \& Littlejohn, G. O. (2007). Measuring quality of life in rheumatic conditions. Clinical Rheumatology, 26, 671-673. https://doi.org/10.1007/s100670060450-8.

Wentz, K. A., Lindberg, C., \& Hallberg, L. R. (2004). Psychological functioning in women with fibromyalgia: A grounded theory study. Health Care for Women International, 25, 702-729. https://doi.org/10.1080/07399330490475575.

Wetzel, R. D., Clayton, P. J., Cloninger, C. R., Brim, J., Martin, R. L., Guze, S. B., ... North, C. (2000). Diagnosis of posttraumatic stress disorder with the MMPI: PK scale scores in somatization disorder. Psychological Reports, 87, 535-541. https://doi.org/10. 2466/pr0.2000.87.2.535.

Wolfe, F., Cathey, M. A., Kleinheksel, S. M., Amos, S. P., Hoffman, R. G., Young, D. Y., \& Hawley, D. J. (1984). Psychological status in primary fibrositis and fibrositis associated with rheumatoid arthritis. The Journal of Rheumatology, 11, 500-506.

Wolfe, F., \& Michaud, K. (2009). Outcome and predictor relationships in fibromyalgia and rheumatoid arthritis: Evidence concerning the continuum versus discrete disorder hypothesis. The Journal of Rheumatology, 36, 831-836. https://doi.org/10.3899/ jrheum.080897.

Woo, M., \& Oei, T. P. S. (2006). The MMPI-2 Gender-Masculine and Gender-Feminine scales: Gender roles as predictors of psychological health in clinical patients. International Journal of Psychology, 41, 413-422. https://doi.org/10.1080/ 00207590500412185.

Yamaguchi, A., Kim, M. S., Oshio, A., \& Akutsu, S. (2017). The role of anger regulation on perceived stress status and physical health. Personality and Individual Differences, 116, 240-245. https://doi.org/10.1016/j.paid.2017.03.053.

Yunus, M. B. (2008). Central sensitivity syndromes: A new paradigm and group nosology for fibromyalgia and overlapping conditions, and the related issue of disease versus illness. Seminars in Arthritis and Rheumatism, 37, 339-352. https://doi.org/10.1016/j. semarthrit.2007.09.003. 